\title{
Adult safeguarding under the Care Act 2014
}

\author{
Katherine Johnson, ${ }^{1}$ Billy Boland ${ }^{1}$
}

BJPsych Bulletin (2019) 43, 38-42, doi:10.1192/bjb.2018.71

\author{
${ }^{1}$ Hertfordshire Partnership University \\ NHS Foundation Trust \\ Correspondence to Katherine Johnson \\ (katherine.wilson3@nhs.net) \\ First received 19 Dec 2017, final revision \\ 16 Jul 2018, accepted 3 Aug 2018 \\ (C) The Authors 2018. This is an Open \\ Access article, distributed under the \\ terms of the Creative Commons \\ Attribution-NonCommercial- \\ NoDerivatives licence (http:// \\ creativecommons.org/licenses/by-nc- \\ nd/4.0/), which permits non- \\ commercial re-use, distribution, and \\ reproduction in any medium, provided \\ the original work is unaltered and is \\ properly cited. The written permission of \\ Cambridge University Press must be \\ obtained for commercial re-use or in \\ order to create a derivative work.
}

Summary Safeguarding adults is everybody's business, and it is now standard practice for clinicians to undertake safeguarding training as part of their mandatory training in the UK. Nevertheless, safeguarding work is complex and can involve significant dilemmas for professionals. The Care Act 2014 has introduced a number of differences in the way safeguarding is approached, emphasising the overall wellbeing and choice of the patient rather than merely focusing on their safety. This paper sets out to illustrate evolving safeguarding demand and practice, and aid clinicians in protecting people at risk by describing how they can approach challenging presentations.

\section{Declaration of interest None.}

\section{Keywords Care Act 2014; safeguarding; personalisation; Making Safeguarding Personal.}

\section{Background}

Safeguarding adults in England and Wales is set out in the Care Act 2014. ${ }^{1}$ The new law came in to being in April 2015 and superseded earlier documents that sought to protect vulnerable adults, ${ }^{2}$ or 'adults at risk of harm, ${ }^{3}$ from abuse. The Care Act itself brought together a wide range of social care concerns and activities, including personalisation, social care assessment and Mental Health Act 117 aftercare, as well as safeguarding, in a single statute. ${ }^{4}$ This aimed to create 'a legal framework so key organizations and individuals with responsibilities for adult safeguarding can agree on how they must work together and what roles they must play to keep adults at risk safe. ${ }^{5}$

In Scotland, the Support and Protection Act 2007 'seeks to protect and benefit adults at risk of being harmed'. The Act 'requires councils and a range of public bodies to work together to support and protect adults who are unable to safeguard themselves, their property and their rights'. ${ }^{6}$ In Northern Ireland, Adult Safeguarding Prevention and Protection in Partnership was published in July 2015. ${ }^{7}$ It makes it clear that 'safeguarding is everyone's business and that as good citizens we should all strive to prevent harm to adults from abuse, exploitation or neglect'.

\section{Definitions}

The term 'vulnerable adult' was a term used in No Secrets to describe those adults who may need to be subject to safeguarding. ${ }^{2}$ However, in 2011, the Law commission recommended that this concept should no longer be used, as the label of vulnerability was not appropriate and could be 'stigmatising, dated, negative and disempowering. ${ }^{3}$ The Care Act uses the term 'adult at risk' and also, at times, 'adult with care and support needs'.

Most doctors will be used to definitions of abuse from statutory training in child protection and adult safeguarding, which is now a mandatory training requirement. Full details of forms of abuse under the Care Act are included in the Care Act statutory guidance. ${ }^{8}$ It should be noted that services now have responsibilities to ensure that carers are also considered within the safeguarding context. Care Act statutory guidance note 14.45 recognises the circumstances in which a carer could be involved in a situation that may require a safeguarding response and provide information on how to manage these.

A 'concern' is used technically in the Act as the point at which the statutory authority is notified by someone that an adult at risk of harm is suspected to be the subject of abuse.

'Enquiries' are the investigations that the statutory authority makes in order to determine whether abuse has taken place, and whether the individual would benefit from safeguarding.

\section{Safeguarding activity}

Statistics gathered in the first 6 months following the implementation of the Care Act suggest that the number of adult safeguarding cases doubled during this period. ${ }^{9}$ During the year following implementation of the Act, the Local Government Association undertook a series of six Care Act stocktakes to help them to understand the implications of 
the Act for local authorities. These stocktakes suggested that the rise in safeguarding referrals has continued, with $73 \%$ of councils involved in stocktake 6 reporting an increase in the levels of activity, and $34 \%$ stating that they had increased greatly. ${ }^{10}$ By contrast, figures gathered by NHS Digital in their Safeguarding Adults: Annual Report for 2015-2016 ${ }^{11}$ indicate that 102970 Section 42 enquiries were reported for the period 2015-2016, compared with 103445 referrals during the period 2014-2015. It is difficult to directly compare statistics across these two reports in light of changes in terms of reference used within the safeguarding proceedings and therefore the reports. However, it should be noted that a total of 184860 safeguarding concerns and 8365 'other enquiries' were reported for the 2015-2016 period, suggesting that the rate of overall referral was greater than the recorded number of enquiries given above. When these are considered alongside the 'referral' rates from the previous year, it appears that the level of safeguarding concerns being raised has indeed increased. Statistics for 2016-2017 support this trend, showing 109145 individuals under a safeguarding enquiry starting during the period measured, an increase of $6 \%$ from the previous year. ${ }^{12}$

\section{Guiding principles}

As with all aspects of the Care Act, the concept of well-being underpins safeguarding practice, with 'protection from abuse and neglect' cited as one of the key elements of promoting individual well-being. ${ }^{8}$ Within this, the Care Act guidance also outlines six fundamental principles for safeguarding (Box 1).

In line with these principles, the Care Act focuses on early identification and prevention of potential abuse and neglect, rather than specifying thresholds for intervention. Any actions proposed should take into account the needs, goals and wishes of the patient, ensuring that their consent is gained before any action is taken. To support this aim, Making Safeguarding Personal (MSP), a sector-led safeguarding initiative, has also been introduced to help develop a more outcome-focused response. ${ }^{13}$

\section{Box 1. Six Principles of Safeguarding ${ }^{8}$}

\section{Empowerment}

People being supported and encouraged to make their own decisions and informed consent

Prevention

It is better to take action before harm occurs

Proportionality

The least intrusive response appropriate to the risk presented Protection

Support and representation for those in greatest need

Partnership

Local solutions through services working with their communities; communities have a part to play in preventing, detecting and reporting neglect and abuse

Accountability

Accountability and transparency in safeguarding practice
The MSP 'temperature check' in $2016^{14}$ recorded a number of positive outcomes in places where MSP was being implemented. Patients reported feeling more in control, with professional meetings declining but smaller patient meetings becoming more common. Overall, the results suggested that while MSP takes no longer than traditional approaches to implement, there is evidence to suggest that it leads to better outcomes and savings in time and resources.

\section{Responsibilities}

'Effective safeguarding cannot be achieved without a large number of organizations and individuals working closely together, and there being an explicit recognition that safeguarding is everyone's concern. ${ }^{15}$

The local authority is required under Section 42 of the Care Act to take a leading role in coordinating safeguarding enquiries, and may do this either through making enquiries themselves or by ensuring that others do so. Guidance for carrying out Section 42 enquiries is set out in paragraphs 14.63-14.67 of the Care Act Statutory Guidance. ${ }^{8}$ Section 43 of the Care Act also requires local authorities to establish a Safeguarding Adults Board for its area, with the objective of helping and protecting adults that meet safeguarding eligibility criteria, through coordinating and ensuring the effectiveness of each of its members. A useful diagram showing the simplified responsibilities of key parties can be found in the Safeguarding Adults paper produced by the Care Quality Commission (CQC), the Association of Directors of Adult Social Services, NHS England, the Local Government Association and the Association of Chief Police Officers. ${ }^{16}$

Alongside local authorities and other partner agencies, individual clinicians should seek to work with individuals at an early stage to promote well-being and independence, with the aim of preventing abuse and neglect from occurring. ${ }^{15}$ Further to this, the focus should be upon identifying abuse or neglect early and raising a safeguarding concern. Care Act guidance states: 'No professional should assume that someone else will pass on information which they think may be critical to the safety and wellbeing of the adult. If a professional has concerns about the adult's welfare and believes they are suffering or likely to suffer abuse or neglect, then they should share the information with the local authority and, or, the police if they believe or suspect that a crime has been committed. ${ }^{8}$ The safeguarding process can be time consuming, and it is important that clinicians continue to offer appropriate care and treatment to the patient. Where appropriate, clinicians should also attend safeguarding meetings in order to provide a more cohesive and robust plan of support.

Although not all concerns will be escalated to become Section 42 enquiries, this will be decided by the relevant safeguarding team, who will have overall responsibility for the decision on whether an enquiry is required. The team will consider the criteria as outlined in S.42(1) Care Act (Box 2). They will also consider issues such as mental capacity ${ }^{17}$ and consent, which will be explored in more detail in the case examples below.

Where clinicians have concerns that important factors are not being acknowledged, these can be raised with the enquiry officer and through initial strategy discussions and 


\section{Box 2. Care Act Safeguarding eligibility criteria}

(1) This section applies where a local authority has reasonable cause to suspect that an adult in its area (whether or not ordinarily resident there):

(2) has needs for care and support (whether or not the authority is meeting any of those needs);

(3) is experiencing, or is at risk of, abuse or neglect; and

(4) as a result of those needs is unable to protect himself or herself against the abuse or neglect or the risk of it.

case conferences, which will be held during the safeguarding enquiry process. All individuals involved in the process will be included in determining whether allegations of abuse are substantiated and in developing an appropriate plan with the patient. Whereas under previous guidance, the emphasis was often on taking professionally proscribed measures to ensure patient safety, statutory Care Act guidance states that 'professionals and staff should not be advocating "safety" measures that do not take account of individual well-being, as defined in Section 1 of the Care Act'. ${ }^{8}$ As in the assessment of social care needs, practitioners should approach safeguarding concerns in an inclusive, outcomesfocused, person-centred manner, and the emphasis should be on 'sensible risk appraisal, not risk avoidance'. ${ }^{18}$ It should be made clear to the individual that they will be included at all stages of the enquiry and that factors such as their wishes, preferences, history and lifestyle will be taken into account throughout the process. Outcomes should be primarily patient determined. While there may be occasions when views of those involved in the process differ, decisions are made in a multidisciplinary manner with the patient's wishes at the forefront, with overall responsibility for reaching consensus falling to the safeguarding manager.

\section{Safeguarding dilemmas}

The case studies below highlight some of the factors and considerations which may be pertinent to safeguarding processes.

\section{Case Example 1: Cheryl - Consent, Coercion and Domestic Violence}

Cheryl is a 30-year-old woman with a diagnosis of severe anxiety and depression. She is living with her partner, Julian, and two children, both of whom are under a Child Protection Plan. There have been a number of concerns raised over recent months about Julian, who will often present as verbally aggressive towards professionals. Julian will also ensure that he is present at all of Cheryl's appointments.

Cheryl comes to her out-patient appointment with a black eye which Julian states is due to walking into a door frame. Her psychiatrist manages to speak to Cheryl alone and Cheryl tells her that in fact Julian has hit her the evening before. Cheryl asks her psychiatrist not to tell anyone and says that she does not want police involved or for any action to be taken. Cheryl's psychiatrist feels that Cheryl has capacity to make this decision, but is concerned about the risks to Cheryl and her children.

Cheryl's psychiatrist raises a Safeguarding Adults concern and also contacts Children's services to ensure they are aware of the incident.

Unlike previous guidance, which emphasised the duty to report and act on all allegations of abuse, the Care Act emphasises empowerment and the patient's right to choice and control over how and with whom information is shared. In this instance, Cheryl is refusing consent to contact police or for a safeguarding investigation to take place. Since Cheryl has capacity to refuse to report abuse to police or for a safeguarding enquiry to be undertaken, a risk assessment will need to be made in regards to whether others are at risk (public interest), a serious crime is taking place (public interest) or Cheryl's life is in danger (vital interest). In line with principles of protection and proportionality, if there is an identified risk in either of these areas, the investigating team may decide to overrule their consent and continue with the safeguarding investigation, involving only professionals and not friends or family members.

In light of Julian's behaviour, consideration should also be given to whether Cheryl's decision is being made under the influence of coercion and control, in which case Cheryl's consent may be overridden and a safeguarding investigation commenced. This new offence of 'coercive and controlling behaviour in intimate and familial relationships' was introduced into the Serious Crime Act 2015 as a way of providing better protection to victims experiencing continuous abuse. ${ }^{8}$ In cases such as these, the individual may present as having capacity in relation to a decision but in fact be unable to make this decision owing to coercion or control. In these cases, the individual will not fall under the auspice of the Mental Capacity Act. This kind of enquiry is often complex and will require a range of professionals to work with the person to identify appropriate safeguarding options. In serious cases, the situation may ultimately require application to the inherent jurisdiction of the High Court, ${ }^{15}$ who may legally be able to act against the wishes of the individual to safeguard them from further harm. Similarly, police now have the ability to use a Domestic Violence Protection Order under Sections 24-33 of the Crime and Security Act 2010 to remove an alleged perpetrator from the family home for a period of up to 28 days with or without consent from the person alleged to be experiencing abuse. ${ }^{19}$

Should it be decided that safeguarding needs to proceed, with or without Cheryl's consent and involvement, there is a need to undertake 'safe enquiry', ensuring that any investigation does not increase risk to Cheryl. The Local Government Association guide to adult safeguarding and domestic abuse ${ }^{20}$ provides a useful and comprehensive guide to dealing with these situations within the safeguarding context.

Finally, if Cheryl refuses consent and none of the above risk factors are present, this decision should be respected and Cheryl should be supported in considering other avenues outside the safeguarding agenda. Information may still need to be shared with children's services if there is 
a perceived risk to the children, which will need to be addressed under child safeguarding procedures.

\section{Case Example 2: Layla - Unintentional Abuse, Carer Safeguarding and Mental Capacity}

Layla is a 77-year-old woman with physical mobility difficulties and early symptoms of Alzheimer's disease. She is currently in a relationship with Giles, a 78-year-old man who also has physical mobility issues.

Layla and Giles both attend Layla's Care Programme Approach meeting, during which Layla's psychiatrist notices that Layla's hair and clothes are unclean and she has lost weight. He asks Layla about this, who replies that Giles does not help her with her personal hygiene or give her food regularly. Giles explains that he is doing his best but is struggling to care for Layla at the moment owing to his physical health, and that he did not want to contact anyone for help as Layla does not want carers involved. He also discloses that he has found caring for Layla more difficult recently, as on a number of occasions she has lashed out at him and caused him minor injuries.

Layla's psychiatrist is concerned that Layla is being neglected and raises a safeguarding concern.

This case study, while on the face of it simple, in fact outlines complex issues around unintentional abuse, carer safeguarding and mental capacity.

In this case study, a safeguarding alert has been raised owing to what appears to be unintentional neglect of Layla, which has arisen because Giles is struggling to care for her. Unintentional abuse is a recognised issue under the Care Act, and guidance is clear that the unintentional nature of this does not change the fact that it is a form of abuse or make the need for action any less important.

In this case example, professionals will need to consider Layla's capacity in relation to a range of safeguarding-related decisions, for example, whether she has capacity to decide whether to allow carers into the home, and whether she can consent to information being shared as part of a safeguarding enquiry. ${ }^{15}$ The Care Act works together with the Mental Capacity Act 2005, and if Layla is found to lack capacity, an Independent Mental Capacity Advocate (IMCA) must be made available to her. Unlike most best-interests decision situations, an IMCA may be required even if there is an appropriate friend or family member who could support Layla.

If Layla is found to have capacity in these areas but also appears to have substantial difficulty in engaging with safeguarding processes, it may be appropriate for a Care Act Advocate to be involved. This is a new role under the Care Act which is used where a person with capacity demonstrates substantial difficulty in being involved in decision-making and does not have an appropriate friend or family member to support them. Where there is no appropriate individual, the local authority must provide an independent advocate. ${ }^{21}$

Also pertinent in this case is that one of the major changes to safeguarding processes introduced by the Care Act is the need to provide safeguarding responses for carers who may be experiencing abuse due to their caring role. Since it has been identified that Giles is experiencing physical abuse from Layla in the course of his caring role, this avenue will need to be considered as a framework for providing him with appropriate support. Although the primary focus is likely to remain on safeguarding Layla, consideration will also need to be given to providing a more appropriate package for Giles as carer to help prevent further abuse to both parties. ${ }^{8}$ In this instance, there is no indication that Giles lacks capacity; however, it should be remembered that where an alleged perpetrator lacks mental capacity, they are entitled to support from an IMCA throughout the safeguarding proceedings. ${ }^{8}$

\section{Case Study 3: Alexis - Organisational Abuse}

Alexis is a 42-year-old Black British man living in a residential placement owing to his moderate learning disability and physical mobility issues. Alexis attends a routine out-patient appointment, during which he discloses that one of the staff members at the placement has left him sitting in the bath for an extended period of time on a number of occasions. Alexis also shares some racially derogatory names which he says the staff member has been calling him when he asks for help. Alexis's psychiatrist decides to raise a safeguarding concern.

This case example allows us to consider issues round organisational abuse, including neglect and poor practice within an institution or specific care setting, and action which will need to be taken in these instances, as set out in the Care Act statutory guidance. ${ }^{8}$

In situations such as this, the safeguarding investigation will need to include Alexis's residential placement. The placement should be made aware that, as instructed by Care Act guidance, where a complaint or allegation has been made against a member of staff, they 'should be made aware of their rights under employment legislation and any internal disciplinary procedures'.

The local authority does not have the right to direct Alexis' care home as to what actions to take against their staff; however, they should report concerns to the CQC and continue to monitor the situation. Since this is a care setting, the local authority must also advise other placing authorities of the concerns so that appropriate measures can be taken to safeguard all other residents as well as Alexis. Since Section 44 of the Mental Capacity Act makes wilful neglect or mistreatment of an adult who lacks capacity a criminal offence, should Alexis be deemed to lack capacity, police involvement may be required in the safeguarding process. ${ }^{15}$

\section{Conclusion: implications for patients and carers}

The introduction of the Care Act 2014 has had a number of implications for patients and carers requiring support under the safeguarding framework. One of the positive developments in regards to individual empowerment is that the Act places a greater emphasis on individual selfdetermination and desired outcomes. Patients now have a more robust framework protecting their rights to make decisions about their lives, with new advocacy requirements ensuring that their voices are heard. Prevention principles have removed some of the previous thresholds which would have prevented those in the early stages of abuse or neglect from being overlooked, and require services to be more proactive in preventing the escalation of abuse

However, it could be argued that the Care Act's emphasis on patient outcomes and goals could come at the price of leaving some individuals unsafeguarded who would previously have been supported under a less flexible 
framework. Services may need to develop new ways of responding to these concerns, ensuring that front-line staff across the multidisciplinary team work together to ensure that needs are met and risks are mitigated as far as possible. There are also questions over where this leaves family members, friends and other members of social networks who will continue to worry about the well-being of the vulnerable person. There is scope under Care Act legislation for support to be offered to carers under the safeguarding framework, and it may be that support can be offered to carers in this situation. For example a carer's assessment may be considered to discuss the effects of the caring role, including worry caused by these concerns.

\section{About the authors}

Katherine Johnson is a Think Ahead consultant social worker, Hertfordshire Partnership University NHS Foundation Trust, UK; Billy Boland is a consultant psychiatrist in community psychiatry, Hertfordshire Partnership University NHS Foundation Trust and vice chair (elected), Faculty of General Adult Psychiatry, Royal College of Psychiatrists, UK

\section{References}

1 UK Government. Care Act. 2014.

2 Department of Health and Social Care. No Secrets: Guidance on Protecting Vulnerable Adults in Care. 2017 (www.gov.uk/government/publications/ no-secrets-guidance-on-protecting-vulnerable-adults-in-care).

3 Safeguarding Partnership Board Adults. UK Law Commission Review of Adult Social Care. 2017 (www.proceduresonline.com/jersey/adults/ chapters/p_law_commission.html).

4 Barnes D, Boland B, Linhart K, Wilson K. Personalisation and social care assessment: the Care Act 2014. BJPsych Bull 2016; 41(3): 176-80.

5 Department of Health and Social Care. Care Act Factsheets. 2017 (www. gov.uk/government/publications/care-act-2014-part-1-factsheets/careact-factsheets\#factsheet-7-protecting-adults-from-abuse-or-neglect).

6 Scottish Government. Adult Support and Protection. Gov.scot, 2017 (http://www.gov.scot/Topics/Health/Support-Social-Care/Adult-SupportProtection, accessed 18 December 2017).

7 Department of Health, Social Services and Public safety. Adult Safeguarding: Prevention and Protection in Partnership. 2017 (https://www.health-ni.gov. uk/sites/default/files/publications/dhssps/adult-safeguarding-policy.pdf).
8 Department of Health and Social Care. Care and Support Statutory Guidance. 2017 (www.gov.uk/government/publications/care-act-statutory-guidance/ care-and-support-statutory-guidance).

9 Community Care. Care Act Triggers Surge in Safeguarding Cases. 2017 (www.communitycare.co.uk/2016/03/16/care-act-triggers-surge-safe guarding-caseloads/).

10 Local Government Association. Care Act 2014: Results of Local Authority Stocktake: Stocktake 6. 2017 (www.local.gov.uk/sites/default/files/ documents/stocktake-6-report-pdf-43-675.pdf).

11 NHS Digital. Safeguarding Adults: Annual Report, England 2015-16 Experimental Statistics. 2017 (www.gov.uk/government/uploads/system/uploads/attachment_data/file/557866/SAC_1516_report.pdf).

12 NHS Digital. Safeguarding Adults Collection: Annual Report England 2016-17. 2017 (http://digital.nhs.uk/catalogue/PUB30145).

13 Local Government Association. Making Safeguarding Personal. 2017 (www.local.gov.uk/topics/social-care-health-and-integration/adult-socialcare/making-safeguarding-personal).

14 Association of Directors of Adult Social Services. Making Safeguarding Personal Temperature Check. ADASS, 2016 (https://www.adass.org.uk/ making-safeguarding-personal-temperature-check-2016/).

15 Social Care Institute for Excellence. Adult Safeguarding Practice Questions. 2015 (www.scie.org.uk/care-act-2014/safeguarding-adults/ adult-safeguarding-practice-questions/index.asp).

16 Local Government Association. Safeguarding Adults: Roles and Responsibilities in Health and Care Services. 2014 (www.cqc.org.uk/sites/ default/files/20140416_safeguarding_adults_-_roles_and_responsibilities_ __revised_draf....pdf).

17 UK Government. Mental Capacity Act. 2005.

18 Skills for Care. Briefing: Care Act Implications for Safeguarding Adults. 2014 (www.skillsforcare.org.uk/Document-library/Standards/Care-Act/learningand-development/care-act-implications-for-safeguarding-adults-briefing. pdf).

19 Domestic Violence Protection Orders Guidance. 2016 (https://assets.publishing.service.gov.uk/government/uploads/system/uploads/attachment data/file/575363/DVPO_guidance_FINAL_3.pdf)

20 Local Government Association. Adult Safeguarding and Domestic Abuse: A Guide to Support Practitioners and Managers. 2015 (www.local.gov.uk/ sites/default/files/documents/adult-safeguarding-and-do-cfe.pdf).

21 Social Care Institute for Excellence. Independent Advocacy under the Care Act. SCIE, 2014 (www.scie.org.uk/care-act-2014/advocacy-services/ commissioning-independent-advocacy/duties/independent-advocacycare-act). 